\title{
Differential regulation of Apak by various DNA damage signals
}

\author{
Shan Wang · Chunyan Tian · Tingting Xiao • \\ Guichun Xing · Fuchu He - Lingqiang Zhang • \\ Hong Chen
}

Published online: 10 September 2009

(C) Springer Science+Business Media, LLC. 2009

Erratum to: Mol Cell Biochem (2009)

DOI 10.1007/s11010-009-0218-y

In this article, the name of the third co-author is given as Tingtiang Xiao. The name is misspelled. Her correct name should read "Tingting Xiao". Everything else in this article remains correct.

The online version of the original article can be found under doi:10.1007/s11010-009-0218-y.

S. Wang · H. Chen $(\bowtie)$

College of Animal Science and Technology, Shaanxi Key Laboratory of Molecular Biology for Agriculture, Northwest A\&F University, 712100 Yangling, Shaanxi, China

e-mail: chenhong1212@263.net

S. Wang $\cdot$ C. Tian $\cdot$ T. Xiao $\cdot$ G. Xing $\cdot$ F. He $\cdot$ L. Zhang $(\bowtie)$ State Key Laboratory of Proteomics, Beijing Proteome Research Center, Beijing Institute of Radiation Medicine,

27 Taiping Road, 100850 Beijing, China

e-mail: zhanglq@nic.bmi.ac.cn

H. Chen

Institute of Cellular and Molecular Biology, Xuzhou Normal

University, 221116 Xuzhou, Jiangsu, China 